\title{
Major Effects of Sensory Experiences on the Neocortical Inhibitory Circuits
}

\author{
Yuanyuan Jiao, ${ }^{1,2}$ Chunzhao Zhang, ${ }^{1}$ Yuchio Yanagawa, ${ }^{3}$ and Qian-Quan Sun ${ }^{1,2}$ \\ ${ }^{1}$ Department of Zoology and Physiology and ${ }^{2}$ Neuroscience Program, University of Wyoming, Laramie, Wyoming 82071, and ${ }^{3}$ Department of Genetic and \\ Behavioral Neuroscience, Gunma University Graduate School of Medicine and Solution-Oriented Research for Science and Technology, Japan Science and \\ Technology Corporation, Maebashi 371-8511, Japan
}

During postnatal development, sensory experiences play critical roles in the refinement of cortical connections. However, both the process of postnatal experience-dependent maturation of neocortical inhibitory networks and its underlying mechanisms remain elusive. Here, we examined the differential properties of intracortical inhibitory networks of layer IV in "sensory-spared" and "sensorydeprived" cortices of glutamate acid decarboxylase 67 (GAD67)-green fluorescent protein (GFP) ( $\Delta$ neo) and wild-type mouse. Our results showed that row D whisker trimming (WT) begun at postnatal day 7 (P7), but not after P15, induced a robust reduction of parvalbumin (PV) expression, measured by the PV/GFP ratio and PV cell densities, in the deprived barrels. WT also induced a robust reduction in the number of inhibitory perisomatic varicosities and synaptic GAD65/67 immunoreactivities in spiny neurons of the deprived barrels. Although the GAD65/67 expressions in interneurons were also downregulated in the deprived barrels, the GFP expression remained unchanged. Patch-clamp recording from spiny cells showed a 1.5-fold reduction of intracortical evoked IPSCs (eIPSCs) in deprived versus spared cortices. The reduction in eIPSCs occurred via changes in presynaptic properties and unitary IPSC amplitudes. Miniature IPSCs showed subtle but significant differences between the two experimental conditions. In addition, properties of the IPSCs in deprived barrels resemble those of IPSCs recorded in immature brains (P7). Together, these results suggest that the properties of local intracortical inhibitory networks are modified by sensory experiences. Perisomatic inhibition mediated by PV-positive basket cells is pruned by sensory deprivation.

Key words: development; plasticity; barrel cortex; interneuron; GABA; somatosensory

\section{Introduction}

Sensory experience drives plasticity of the body map in developing and adult sensory cortices (Feldman and Brecht, 2005). Currently, paramount evidence shows that the extent of intracortical excitatory synaptic connections in sensory cortices is closely related to sensory experiences at critical periods. There is increasing evidence suggesting that the amount of inhibitory neurotransmitter (GABA), its receptors, and the number of synapses are also correlated with levels of neuronal activity (Micheva and Beaulieu, 1995; Knott et al., 2002; Morales et al., 2002; Heinen et al., 2004). Recently, cortical inhibition has been shown to play vital roles in the formation of critical periods of sensory plasticity. In the visual cortex, selective genetic deletion of fast-synaptic GABAmediated inhibition prevents ocular dominance plasticity (Hensch et al., 1998). In contrast, pharmacological enhancement of activity-dependent GABA transmission can prematurely en-

\footnotetext{
Received April 10, 2006; revised July 10, 2006; accepted July 19, 2006.

This work was supported by National Institutes of Health-National Center for Research Resources Grants P20 RR015553, P20 RR16474 - 04, and RR15640 (Q.Q.S.) and by a grant-in-aid for Scientific Research from the Ministry of Education, Culture, Sports, Science, and Technology of Japan (Y.Y.). Confocal microscopy was performed in the University of Wyoming Microscopy Core Facility. We thank Andrew N. Young for providing valuable comments. Y. Jiao is a recipient of University of Wyoming Neuroscience Graduate Assistantship. We thank the two anonymous reviewers for their constructive criticism of previous versions of this manuscript.

Correspondence should be addressed to Dr. Qian-Quan Sun at the above address. E-mail: neuron@uwyo.edu. DOI:10.1523/JNEUROSCI.2478-06.2006

Copyright $\odot 2006$ Society for Neuroscience $\quad$ 0270-6474/06/268691-11\$15.00/0
}

hance the ocular dominance plasticity (Fagiolini et al., 2004). In normal wild-type animals, enhancing local existing GABA transmission does not perturb visual responsiveness but does widen column spacing (Hensch and Stryker, 2004). This suggests that local cortical inhibitory synapses might modulate incoming thalamocortical (TC) inputs. However, direct experimental evidence linking specific structural and functional changes of GABAergic inhibitory networks with previous sensory experiences in vivo is lacking.

How do changes of inhibitory synapses contribute to the formation of critical periods? Rodent whisker sensory input is represented somatopically in the barrel field of layer IV of S1 neocortex (Woolsey and Van der Loos, 1970). At the level of the cortical circuit, competitive interactions between barrel and septal regions are important in the establishment of precise intracortical circuits in the barrel cortex (Shepherd and Svoboda, 2005). In the barrel cortex of rodents, intrabarrel inhibition has been hypothesized to play an important role in the sensory-mediated refinement of receptive fields (Alonso and Swadlow, 2005). We therefore hypothesized that activity-dependent regulation of intracortical inhibitory circuits was necessary for plasticity of the body map representation in barrel cortex. The first step toward testing this hypothesis will be to examine whether cortical inhibitory networks are differentially modulated in "sensorydeprived" and "sensory-spared" cortices. In barrel cortex, disyn- 
aptic feedforward inhibition, mediated by direct TC excitation of interneurons, is a critical part of the sensory gating process (Nelson, 1991; Agmon et al., 1996; Vidyasagar et al., 1996; Alonso and Swadlow, 2005). Strong, reliable unitary feedforward inhibition onto excitatory neurons in layer IV is mediated by parvalbumin (PV)-positive and fast-spiking basket cells, which are the main providers of sensory feedforward inhibitory responses in the barrel cortex (Sun et al., 2006). Whether synaptic properties of this important intracortical inhibitory network show any experiencedependent plasticity is unclear. We therefore focused on elucidating the effects of sensory deprivation on parvalbumin-positive interneurons and intracortical evoked inhibitory synaptic responses.

\section{Materials and Methods \\ Animals and treatment groups}

We used glutamate acid decarboxylase 67 (GAD67)-green fluorescent protein (GFP) ( $\Delta$ neo) mice, in which GFP is selectively expressed under the control of the endogenous GAD67 gene promoter (Tamamaki et al., 2003). In this study, these transgenic mice were called GAD67-GFP mice for simplicity. The GAD67-GFP transgenic mouse line was used to study the effects of whisker removal on the maturation of inhibitory networks in sensorily spared and deprived cortices in the adolescent barrel cortex. Mice were divided into three groups: one group of mice had row D whiskers (in the left mystacial pad) removed, another group of mice had all whiskers (rows A-E, in the left mystacial pad) removed, and the third group were sham-treated normal mice. Animals in the experimental groups began to have whiskers (only whiskers of the left mystacial pad) removed at neonatal day 7 (or 15), and this process lasted until the mice were $30 \mathrm{~d}$ of age. Additional groups (whisker trimmed and controls) of wild-type, GFP-negative mice were used as control groups. Care was taken to ensure that whisker removal did not cause any excessive bleeding or damage to the whisker follicle. At postnatal day 30 (P30), mice were given a lethal injection of Nembutal and perfused intracardially with $0.9 \%$ sodium chloride, followed by $4 \%$ paraformaldehyde. The brain was then removed, and the whole cortex was dissected. To be processed for tangential sections, the left and right cortices were flattened between two glass slides to a thickness of $\sim 2 \mathrm{~mm}$. The tissues were cryoprotected in $30 \%$ sucrose and then cut into 30 - to $40-\mu \mathrm{m}$-thick tangential sections. Thalamocortical sections were prepared based on methods described by Agmon and Connors (1991). Alternative sections from the barrel cortex were processed for cytochrome oxidase (CO) and PV-3,3'diaminobenzidine tetrahydrochloride (DAB) (or GFP-DAB) staining.

\section{Immunohistochemistry}

$D A B$ staining. Sections were incubated in $0.6 \% \mathrm{H}_{2} \mathrm{O}_{2}$ for $30 \mathrm{~min}$, PBS washed, switched to $50 \%$ alcohol for $10 \mathrm{~min}$, PBS washed, and then incubated in TBS with $0.5 \%$ Triton X-100, $2 \%$ BSA, and 10\% normal goat serum for $2 \mathrm{~h}$, and incubated in primary antibodies directed against the following: PV (1:1000; Calbiochem, La Jolla, CA) or GFP (1:1000; polyclonal chicken anti-GFP; Millipore, Billerica, MA) overnight. The next day, PBS-rinsed sections were incubated in biotinylated goat antirabbit IgG (Vector Laboratories, Burlingame, CA) for PV or biotinylated goat anti-chicken IgG (Vector Laboratories) for GFP and then incubated in Vectastain ABC kit (Vector Laboratories) overnight. After PBS washing, sections were developed in DAB (Sigma-Aldrich, St. Louis, MO) for 5-15 min, TBS washed, mounted, dehydrated, cleared, and coverslipped. Reconstructed neurons were quantitatively analyzed with Neurolucida and NeuroExplorer (MicroBrightField, Williston, VT).

CO histochemistry. Methods for CO staining were modified from the method published previously by Wong-Riley (1979). Sections were incubated in DAB (Sigma-Aldrich), cytochrome $c$ (type III; SigmaAldrich), and sucrose in $0.1 \mathrm{~m}$ phosphate buffer, $\mathrm{pH} 7.4$, for $3 \mathrm{~h}$ and then TBS washed, mounted, and coverslipped. Reconstructed contours of barrel structures and slice outlines were quantitatively analyzed with NeuroExplorer (MicroBrightField).

Fluorescent labeling. Sections were incubated in $0.6 \% \mathrm{H}_{2} \mathrm{O}_{2}$ for $30 \mathrm{~min}$, PBS washed, switched to $50 \%$ alcohol for $10 \mathrm{~min}$, PBS washed, and then incubated in TBS with $0.5 \%$ Triton X-100, 2\% BSA, and 10\% normal goat serum for $2 \mathrm{~h}$ and incubated in primary antibodies directed against PV (1:1000; Calbiochem) overnight. The next day, after PBS rinsing, sections were incubated in Alexa Fluor 594 and goat anti-rabbit IgG (heavy and light chains; 1:1000; Invitrogen, Carlsbad, CA) for PV for $3 \mathrm{~h}$ and then rinsed, mounted, and coverslipped. The immunofluorescent specimens were examined using an epifluorescence microscope (Zeiss, Thornwood, NY) equipped with AxioCam digital color camera. Doubleimmunofluorescent images were analyzed using an AxioVision LE imaging suite (Zeiss). The other primary antibodies used were a polyclonal rabbit anti-GAD65/67 (1:1000; Millipore) and a polyclonal rabbit antineurofilament (1:500; Millipore).

\section{Identification of barrels}

Identification of barrels was achieved via aligning imaging data with underlying CO traced maps. The present study used a computer-aided image analysis system to determine the changes in PV-positive and GFPpositive neuronal density in the barrel cortex after whisker trimming. The image of the CO-stained cortical sections (30-40 $\mu \mathrm{m}$ in thickness) was used as a reference and imported into the NeuroExplorer program (MicroBrightField) to trace barrel-related columns throughout layer IV of the barrel cortex (see Figs. 1,2). Photographs of the DAB-stained and/or double-labeled immunofluorescence-stained cortical sections (30-40 $\mu \mathrm{m}$ in thickness) were digitized directly from the microscope images using a CCD (Evolution VF Cooled Monochrome; Media Cybernetics, Silver Spring, MD) camera and imported into Photoshop (version 7.0; Adobe Systems, San Jose, CA) for each brain section. Then, the images of DAB or double-immunofluorescence-stained cortical sections (30-40 $\mu \mathrm{m}$ in thickness) were superimposed over the appropriate trace of CO-stained barrels using an AxioVision LE imaging suite (Zeiss). With this method, the location of the immunohistochemically stained neurons, with regard to the outline of barrels, could be accurately determined. Finally, within the outlined barrel columns of layer IV barrel cortex, the densities of specific marked cells and boutons were analyzed (see Figs. 1-4).

\section{Quantification of inhibitory presynaptic boutons}

To count the number of perisomatic boutons, a Zeiss Axioskop 2FS microscope, equipped with a $100 \times$ oil-immersion plan achromatic objective and a $10 \times$ objective lens, was used. The microscope was equipped with a CCD video camera and was connected to the NeuroExplorer program (MicroBrightField). With the $10 \times$ objective lens, we first identified and outlined the deprived row and spared row and then switched to the $100 \times$ objective. The number of perisomatic boutons was counted in defined regions in individual sections. Perisomatic inhibitory varicosities were defined as small $(0.5-1 \mu \mathrm{m}) \mathrm{PV}$-positive puncta located within 1 $\mu \mathrm{m}$ of a PV-negative cell body that was recognized under differential interference contrast (DIC) microscopy. In a second experiment, the perisomatic presynaptic boutons were determined under confocal fluorescence microscopy as small GFP-positive puncta $(0.5-1 \mu \mathrm{m})$ located $<1 \mu \mathrm{m}$ from a neurofilament (NF)-positive or GAD65/67immunopositive soma (see Fig. 4). Confocal microscopy was performed in the University of Wyoming Microscopy Core Facility. An upright Nikon (Tokyo, Japan) E800 confocal laser-scanning microscope [BioRad (Hercules, CA) Radiance 2100] was used. Laser lines include the following: blue diode laser (405 nm), argon ion laser (457, 477, 488, and $514 \mathrm{~nm})$, HeNe laser (543 nm), and red diode laser (637 nm). AxioVision LE imaging suite software (Zeiss) and its automeasure program were used to study synaptic bouton densities near a spiny neuron and to measure grayscale intensities for GAD65/67 and GFP immunoreactivities (see Fig. 4).

\section{Brain slice preparations and electrophysiological recordings} GAD67-GFP mice (normal or whisker trimmed) were deeply anesthetized and decapitated. The brains were quickly removed and placed into cold $\left(\sim 4^{\circ} \mathrm{C}\right)$ oxygenated slicing medium containing the following (in $\mathrm{mm}): 2.5 \mathrm{KCl}, 1.25 \mathrm{NaH}_{2} \mathrm{PO}_{4}, 10.0 \mathrm{MgCl}_{2}, 0.5 \mathrm{CaCl}_{2}, 26.0 \mathrm{NaHCO}_{3}, 11.0$ glucose, and 234.0 sucrose. TC slices were prepared according to methods described by Agmon and Connors (1991). Tissue slices (300-400 $\mu \mathrm{m}$ ) were cut using a vibratome (TPI, St. Louis, MO), transferred to a 
holding chamber, and incubated $\left(35^{\circ} \mathrm{C}\right)$ for at least $1 \mathrm{~h}$. Individual slices were then transferred to a recording chamber, fixed to a modified microscope stage, and allowed to equilibrate for at least $30 \mathrm{~min}$ before recording. Slices were minimally submerged and continuously superfused with oxygenated physiological saline at the rate of $4.0 \mathrm{ml} / \mathrm{min}$. The physiological perfusion solution contained the following (in $\mathrm{mm}$ ): $126.0 \mathrm{NaCl}, 2.5$ $\mathrm{KCl}, 1.25 \mathrm{NaH}_{2} \mathrm{PO}_{4}, 1.0 \mathrm{MgCl}_{2}, 2.0 \mathrm{CaCl}_{2}, 26.0 \mathrm{NaHCO}_{3}$, and 10.0 glucose. Solutions were gassed with $95 \% \mathrm{O}_{2} / 5 \% \mathrm{CO}_{2}$ to a final $\mathrm{pH}$ of 7.4 at a temperature of $35 \pm 1{ }^{\circ} \mathrm{C}$. The method for identification of the barrel subfield in living TC slices was described in a previous study (Sun et al., 2006). A low-power objective $(2.5 \times)$ was used to identify barrels and thalamic nuclei, and a high-power water-immersion objective $(40 \times)$ with Nomarski optics and infrared video was used to visualize individual neurons (see Fig. 5B). Recording pipettes were fabricated from capillary glass obtained from World Precision Instruments (M1B150F-4; Sarasota, FL) using a Sutter Instrument (Novato, CA) P80 puller and had tip resistances of $2-5 \mathrm{M} \Omega$ when filled with the intracellular solutions below. A Multiclamp 700B amplifier (Molecular Devices, Foster City, CA) was used for voltage-clamp and current-clamp recordings. Patch pipette saline was composed of the following (in $\mathrm{mM}$ ): 100 Cs-gluconate, 10.0 phosphocreatine-Tris, $3.0 \mathrm{MgCl}_{2}, 0.07 \mathrm{CaCl}_{2}$, 4 EGTA, 10.0 HEPES, 4.0 $\mathrm{Na}_{2}-\mathrm{ATP}$, and 1.0 Na-GTP, $\mathrm{pH}$ adjusted to 7.4 and osmolarity adjusted to $280 \mathrm{mOsm} / \mathrm{L}$. Neurobiotin ( $0.5 \%$; Vector Laboratories) was regularly added to the patch pipette solution. Data were accepted for analysis when access resistance in whole-cell recordings ranged from 5 to $8 \mathrm{M} \Omega$ and were stable ( $<25 \%$ change) during the recording. Current- and voltageclamp protocols were generated using pClamp 9.2 software (Molecular Devices). A sharpened bipolar tungsten electrode, placed $\sim 200 \mu \mathrm{m}$ away from recorded cells in the cortical layer IV, was used to activate intracortical fibers. Monosynaptic IPSCs were evoked in spiny neurons with the stimuli and were recorded at a holding potential of $0 \mathrm{mV}$ [at which glutamatergic currents are at a minimum (see Fig. 5C2)]. IPSCs were also verified pharmacologically via sensitivity to $\mathrm{GABA}_{\mathrm{A}}$ antagonist 6-imino3-(4-methoxyphenyl)-1(6H)-pyridazinebutanoic acid hydrobromide (SR95531) (see Fig. 5C2). Miniature IPSCs (mIPSCs) were recorded in the presence of bath perfusion of TTX (100 nM). We used a "near threshold stimulus" approach throughout the experiment to elicit eIPSCs in spiny cells. Experimentally, we increased stimulus intensity gradually, until IPSCs were reliably elicited in mature neurons (Xiang et al., 1998). The stimulus threshold was determined by applying a series of $100 \mu \mathrm{s}$ square pulses whose intensity was increased from 10 to $80 \mu \mathrm{A}$ until detectable responses were obtained. Once the threshold was determined, stimuli with 1.5 -fold of this intensity were used to evoke IPSCs. We then measured the amplitude of the eIPSCs evoked by the near threshold stimulus. However, in the immature neurons (P7), the eIPSCs evoked by the near threshold stimulus had a much higher failure rate (see Fig. 7A1). For quantitative analysis of distribution of evoked IPSCs (see Fig. 8), the distribution of the amplitudes of evoked IPSCs was fitted with multipeak Gaussian distribution (Origin; OriginLab, Northampton, MA) using the following equation:

$$
y=y_{0}+\frac{A}{w \times \sqrt{\frac{x}{2}}} e^{-\frac{2\left(x-x_{0}\right)^{2}}{w^{2}}},
$$

where $y_{0}$ was the baseline offset, $A$ was the total area under the curve from the baseline, $x_{0}$ was the center of the peak, and $w^{2}(\sigma)$ was $\sim 0.849$ the width of the peak at half-height. This model described a bell-shaped curve like the normal (Gaussian) probability distribution function. The center $\left(x_{0}\right)$ represented the mean, and $w / 2$ was the SD. The following chemicals were used: GYKI 52466 [4-(8-methyl-9H-1,3-dioxolo[4,5h] [2,3] benzodiazepin-5-yl)-benzenamine hydrochloride; Tocris Bioscience, Ellisville, MO]; NBQX (1,2,3,4-tetrahydro-6-nitro-2,3-dioxobenzo[f] quinoxaline-7-sulfonamide; Tocris Bioscience); DL-AP5 (Tocris Bioscience); SR95531 (Tocris Bioscience); and TTX (Sigma-Aldrich). Paired (for comparison between deprived and spared barrels in the same animals or between whisker-trimmed and control littermates) and unpaired Student's $t$ tests were used to examine statistical significance between groups.
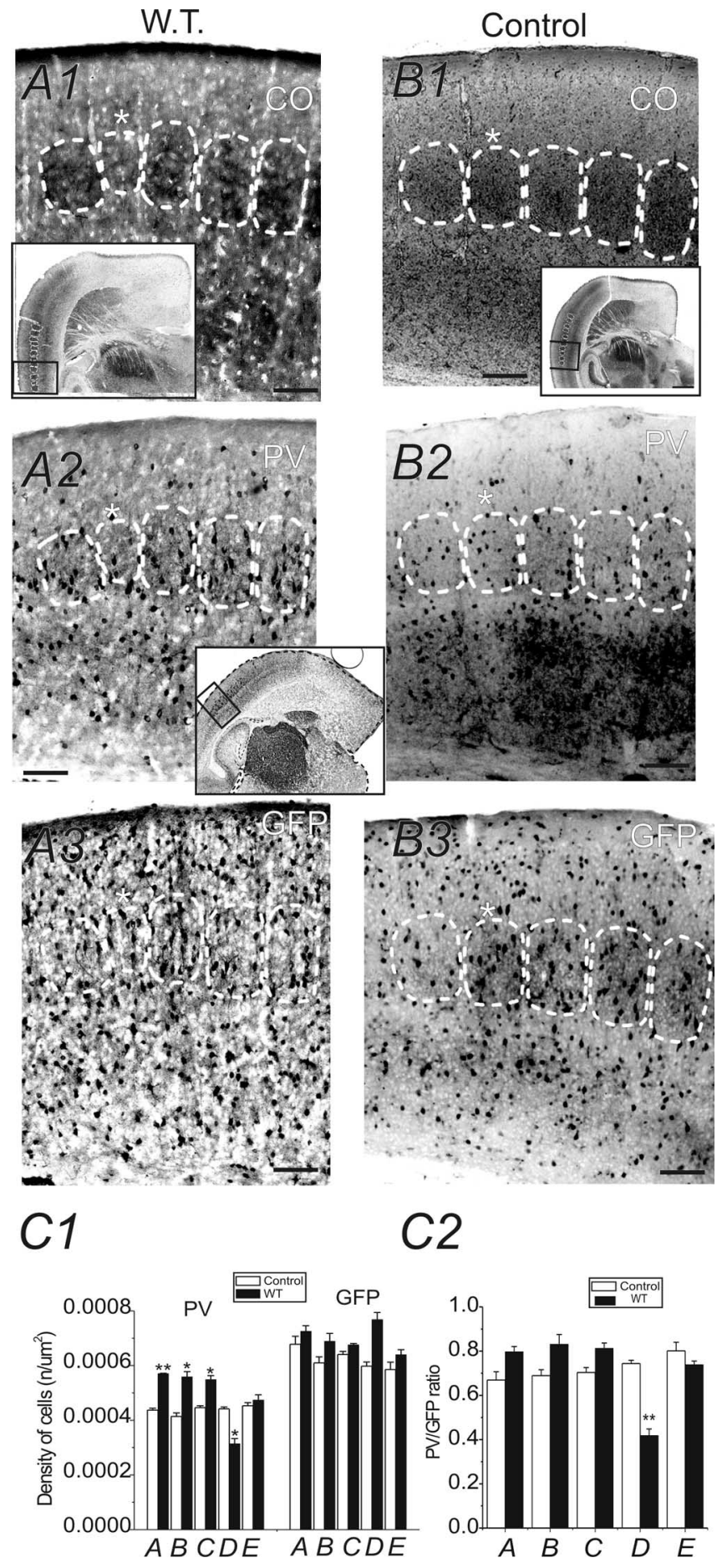

Figure 1. Effects of row-D WT on PV expression in barrel cortex layer IV (TC sections). A1, B1, Photomicrographs of CO-stained TC sections ( $40 \mu \mathrm{m}$ in thickness) from a row-D whiskertrimmed GAD67-GFP mouse (A1) and a control littermate mouse (B1). White dashed lines outline barrels throughout layer IV of the barrel cortex. Asterisks mark row $D$ of the barrel field.

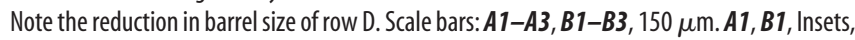
Images of entire TC sections. The boxes in the insets show areas of posteromedial barrel subfield that were enlarged and shown in $\boldsymbol{A} \mathbf{1}$ and $\boldsymbol{B} 1$. Scale bar: $\boldsymbol{B} \mathbf{1}$ inset, $600 \mu \mathrm{m} . \boldsymbol{A 2}, \boldsymbol{A 3}$, Two brain sections (40 $\mu \mathrm{m}$ in thickness) adjacent to the $\mathbf{C}$-stained section of $\boldsymbol{A 1}$. The sections were stained for PV (A2) and GFP (A3). Rows A-E barrel areas of layer IV barrel cortex are shown. B2, $\boldsymbol{B} 3$, Two brain sections adjacent to the section of $\boldsymbol{B} 1$. The sections were stained for $P V(\boldsymbol{B} 2)$ and GFP (B3). C1, Statistical comparison of cell densities (PV-positive and GFP-positive cells) in rows A-E barrels of whisker-trimmed (black bars) and normal (white bars) mice. Only neurons inside the barrels were counted. $\mathbf{C}$, Comparison of PV/GFP ratio in rows A-E barrels of whiskertrimmed (black bars) and normal (white bars) mice. ${ }^{*} p<0.05 ;{ }^{* *} p<0.01 ; n=5$ brains in whisker-trimmed mice and controls, respectively. Error bars represent SEM. 
Results

Differential expression of PV in layer IV GAD67-GFP interneurons in sensorydeprived and -spared cortices

We first examined the effects of WT on PV expression in GAD67-GFP interneurons. Figure $1 A 1$, a photomicrograph of $\mathrm{CO}$ staining in a TC section, showed a decrease in size of the row $\mathrm{D}$ barrel of D-rowdeprived brain compared with the untreated row D barrels (compare Fig. 1B1). A comparison of the densities of PVpositive neurons in row $\mathrm{D}$ of deprived brains and row D barrels of the control brains revealed a significant decrease ( $29 \pm 3 \% ; p<0.05 ; n=5$ brains) in the density of PV-positive neurons in experimental row $\mathrm{D}$ barrel $(0.0003 \pm 0.00005$ $\mu \mathrm{m}^{2}$ ) compared with control row D barrel $\left(0.0004 \pm 0.00003 \mu \mathrm{m}^{2}\right.$ ) (Fig. 1, compare $A 2, B 2 ; C 1)$. In contrast to the deprived row (row D), the densities of PV-positive neurons showed a significant increase in the majority of spared barrels (A, B, and C, but not E) (Fig. 1C1) ( $n=5$ brains) over corresponding barrels in controls. Figure 2, a photomicrograph of tangential sections, further verified a similar reduction of PV-positive interneurons in row $\mathrm{D}$ barrels $\left(0.0005 \pm 0.0001 \mu \mathrm{m}^{2}\right)$ compared with spared row barrels $(0.0006 \pm 0.0001$ $\mu \mathrm{m}^{2}$ ) in row $\mathrm{D}$ whisker-trimmed mice ( $n=3$ brains). The above results suggest that row D WT induces differential effects on the expression of PV, i.e., a robust decrease of PV-positive cell density in barrels corresponding to the deprived row (D) and an increase of PVpositive cell density in spared barrels $(\mathrm{A}-\mathrm{C})$. We hypothesized that removal of all major mystacial whiskers would also induce downregulation of PV expression in all barrel cortical areas. We did not find significant changes in barrel size (A-E) in this experiment (data not shown). However, in Figure 3, our data showed that after rows A-E WT, the mean density of PV-positive neurons $\left(0.0004 \pm 0.00001 \mu \mathrm{m}^{2} ; n=22\right.$ sections from five brains) in experimental mice was significantly decreased $(20 \pm 1 \%$; $p<$ $0.01)$ compared with the control mice $\left(0.0004 \pm 0.00001 \mu \mathrm{m}^{2}\right.$; $n=22$ sections from five brains). These results indicate that PV expression in the barrel cortex correlates well with levels of sensory activities.

A reduction of PV-positive cells could be attributable to either of the following: (1) reduced proliferation or increased apoptosis of PV-type GABAergic cells or (2) downregulation of PV expression in a subpopulation of GABAergic cells. It has been technically difficult to determine which of the two situations occurs in sensory deprivation. We took advantage of the GAD67-GFP mouse, in which $>95 \%$ of GABAergic cells express GFP under the promoter of GAD67 in motor cortex (Tamamaki et al., 2003) and in somatosensory cortex (Q. Q. Sun, unpublished observations). Using this mouse, we counted the GFP-positive cells. Data on the densities of GFP-positive neurons in the barrel cortex of experimentally treated (whisker-trimmed) groups and control groups were also presented in Figures 1-3. As shown in Figure 1,
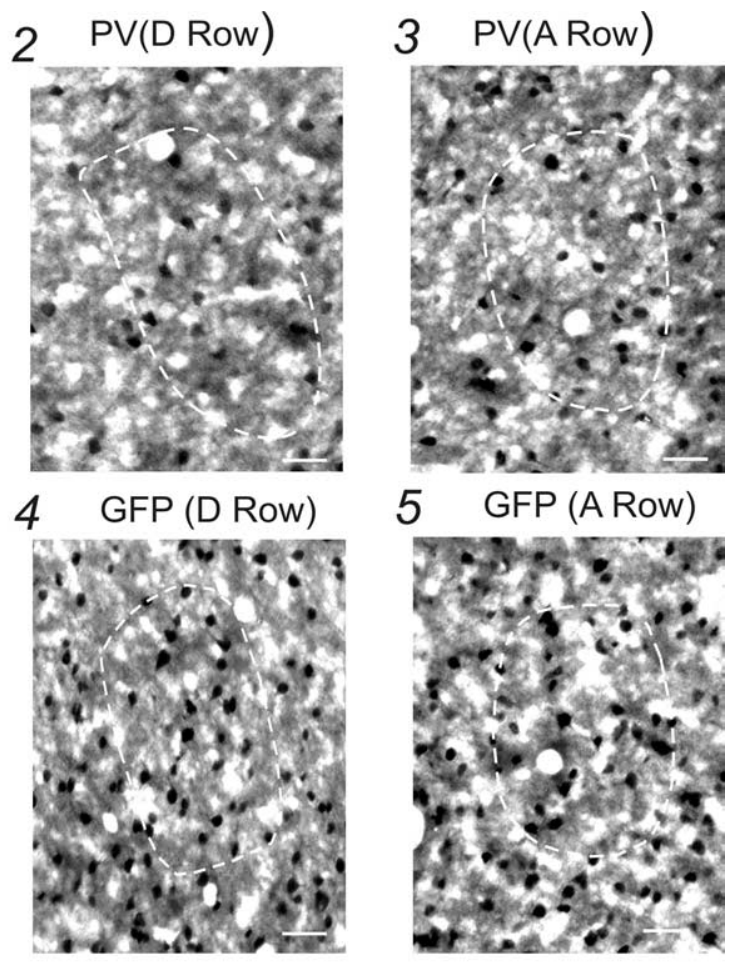

Figure 2. Effects of row-D WT on PV expression in barrel cortex layer IV (tangential sections). A1, Photomicrograph of a neurons inside the barrels were counted. Scale bars, $50 \mu \mathrm{m}$. $\boldsymbol{B}$, Density of PV-positive and GFP-positive neurons in row-D barrels (black bars) and spared barrels (rows $A-C$, white bars). ${ }^{*} p<0.05$. Error bars represent SEM.

the densities of GAD67-GFP-positive neurons in the control row $\mathrm{D}$ barrels did not show significant differences between deprived (D) and spared (A-C and E) barrels and were similar to control brains (Fig. 1, compare $A 3, B 3$; C1). In tangential sections (Fig. 2), results were similar to those seen in TC sections (compare Fig. 1), i.e., no significant changes were found in the densities of GFP cells in different barrels. However, in experiments in which all major mystacial whiskers (rows A-E) were removed, a small but significant increase in GFP-positive cell density (0.00064 \pm $0.00008 \mu \mathrm{m}^{2}$ vs $0.00057 \pm 0.00009 \mu \mathrm{m}^{2} ; n=22$ sections from five brains in each group; $p<0.01$ ) was found in whiskertrimmed brains compared with the controls. These results excluded the possibility that sensory deprivation induced decreased cell proliferation or increased apoptosis of GABAergic interneurons. The PV/GFP ratio showed a significant reduction in deprived cortices (Fig. 3C2) $(p<0.0001)$. We also used doubleimmunofluorescence staining to examine the colocalization of PV in GFP cells. The staining of PV and GFP was observed in neuronal cell bodies in layer IV barrel cortex (Fig. 3). In naive untreated mice, $\sim 80 \%$ of GFP-positive neurons were also PV positive in the barrel areas (Fig. 3A3, yellow), whereas in the whisker-trimmed (rows A-E) sections, the density of PV-positive cells was decreased. Only a few GFP-positive neurons coexisted with PV-positive cells in deprived barrels (Fig. 3, compare A3, $B 3$ ). These results suggest that WT, begun around the onset of whisking behavior $(\sim \mathrm{P} 7)$, can induce profound downregulation of parvalbumin expression in layer IV GABAergic interneurons. 

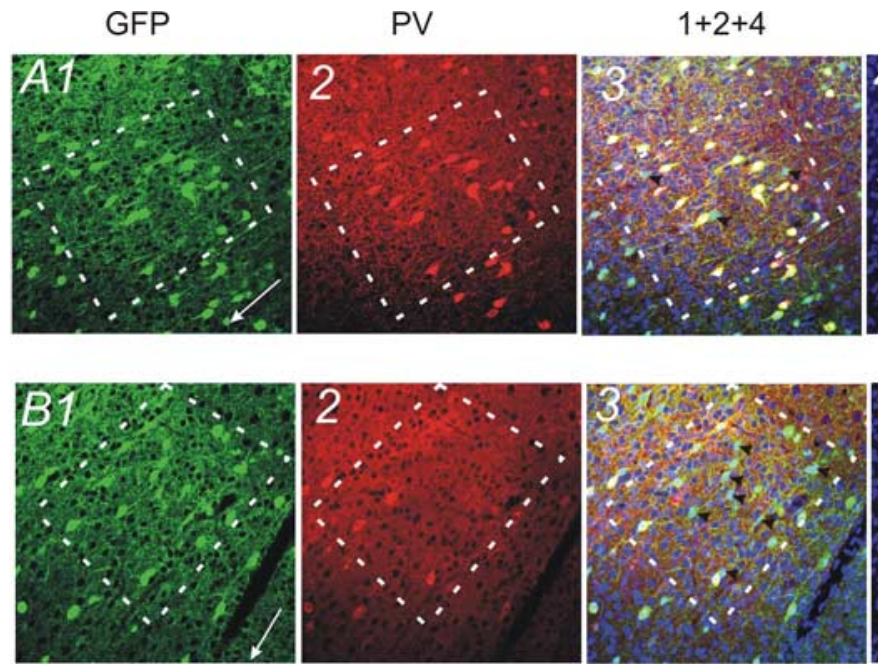

C1
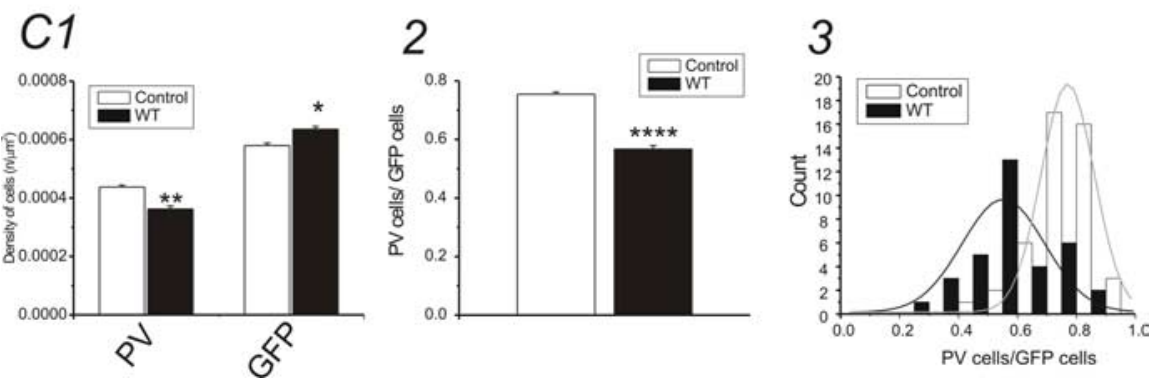

Figure 3. Effects of all-row WT on PV expression in barrel cortex layer IV (TC sections). A, Photomicrographs of tripleimmunofluorescence-stained TC section (30 $\mu$ m in thickness) from control GAD67-GFP mouse. A1-A4, Photomicrographs of GFP (A1; green), PV (A2; red), and nucleus [A4; 4',6'-diamidino-2-phenylindole (DAPI); blue] staining in barrel cortex of a control untreated mouse. $\boldsymbol{A} \mathbf{3}, 0$ verlay of $\boldsymbol{A} \mathbf{1}, \boldsymbol{A}$, and $\boldsymbol{A 4}$. Scale bars, $30 \mu \mathrm{m}$. Dashed white lines outline barrels throughout the barrel cortex. White arrows in $\boldsymbol{A} \mathbf{1}$ and $\boldsymbol{B} 1$ point to the pia surface. $\boldsymbol{B}$, Photomicrographs of triple-immunofluorescence-stained TC section (30 $\mu \mathrm{m}$ in thickness) from a whisker-trimmed (rows A-E) GAD67 mouse. B1-B4, Photomicrographs of GFP (B1; green), PV (B2; red), and nucleus (B4;DAPl; blue) staining in barrel cortex of a whisker-trimmed (rows A-E) mouse. $\boldsymbol{B} 3$, Overlay of $\boldsymbol{B} 1, \boldsymbol{B} 2$, and $\boldsymbol{B} 4$. Scale bars, $30 \mu \mathrm{m}$. Dashed white lines outline barrels throughout the barrel cortex. $A 3, B 3$, Black arrowheads, PV-negative GFP cells. C, Statistical comparison of cell density of GFP-positive and PV-positive cells in barrels of WT-treated (black bars) and control (white bars) mice. C1, the density of PV-positive neurons was significantly reduced $\left({ }^{* *} p<0.01 ; n=5\right.$ brains in control and whisker-trimmed groups, respectively) in barrels of the WT-treated mice. The density of GFP-positive neurons was increased in WT-treated mice $\left({ }^{*} p<0.05 ; n=5\right.$ mice in control and whisker-trimmed groups, respectively). (2, The ratio of PV/GFP-positive neurons in barrel areas of WT-treated (black bar) and control (white bar) mice ( ${ }^{* * *} p<0.0001 ; n=5$ mice in control and whisker-trimmed groups, respectively). C3, Distribution of PV/GFP ratio in control (white bars; $n=5$ mice) and whisker-trimmed (black bars; $n=5$ mice) groups, respectively. A single Gaussian distribution (solid lines) was fitted to the distribution of the count (i.e., number of sections). Error bars represent SEM.

However, the total number of GAD67-GFP cells, which is similar to the total number of GABAergic cells, remained overall unchanged. We also examined whether there was a critical period for the sensory-dependent downregulation of PV expression in barrel cortex. In mice in which WT began in the third postnatal week (P15-P30), we have not found significant changes in the density of PV cells $(0.00038 \pm 0.00006$ vs $0.00042 \pm 0.00008)$ in layer IV ( $n=6$ slices from three brains; no statistical significance; data not shown). Therefore, early sensory experiences are required for preventing the robust downregulation of PV expression. Finally, we examined the effects of sensory deprivation in wild-type and GAD67-GFP-negative mice. In three GFPnegative mice examined, WT begun at P7 also caused a robust reduction in the number of PV cells $(38 \pm 3 \%$; $n=4$ mice for control and deprived, respectively; $p<0.01$ for deprived vs spared) in deprived barrels (D-row whisker trimmed).
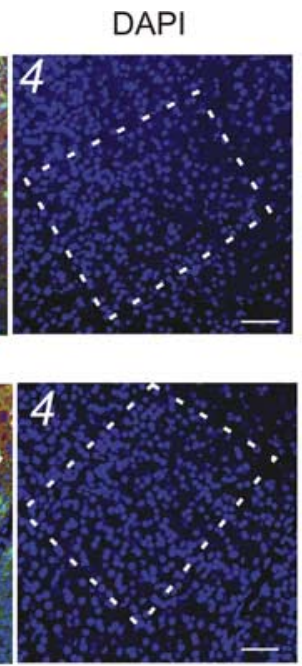

Whisker trimming induced downregulation of perisomatic GABAergic boutons in spiny cells and GAD expression in both spiny neurons and interneurons

In barrel cortex layer IV, the axons of basket cells formed a characteristically dense plexus near spiny cells (McMullen et al., 1994; Sun et al., 2006). In PV or GFP-DAB immunostained sections, the PV- or GFPpositive axons followed a circuitous path between cell bodies, forming abundant perisomatic boutons around unlabeled cells (Fig. 4A1). We named and counted these perisomatic boutons in sections from control and whisker-trimmed mice. A comparison of PV-positive cell boutons in control mice, with PV-positive cell boutons in row D whisker-trimmed mice (Fig. $4 B 1$ ), revealed no change in PV-positive cell boutons in the sensory-spared cortices, but a significant decrease $(25 \pm 3 \%$; ${ }^{* *} p<0.01 ; n=5$ mice) was found in the number of PV-positive cell boutons in the sensory-deprived barrel areas of the whisker-trimmed mice (Fig. 4B1). In addition, using GFP-DAB staining, we studied the number of perisomatic GFPpositive boutons. Our results showed that the number of perisomatic GFP-positive boutons was similar to the PV-positive boutons (Fig. 4B1). Moreover, there was a similar reduction in the number of GFPpositive boutons in deprived barrels (Fig. 4B1) $\left(20 \pm 2 \% ;{ }^{\star} p<0.05 ; n=5\right.$ mice $)$.

To further verify the perisomatic location of GAD67-GFP synapses, we performed double-immunolabeling experiments. The markers we used were intermediate neurofilaments (NF-M), which are typical structures of the neuronal cytoskeleton. In the neocortex of all species examined, the antibodies labeled pyramidal cells (Hayes and Lewis, 1992; Hornung and Riederer, 1999). In barrel cortex, layer IV, NF-M also labeled star pyramidal-like cells. The results showed an abundant overlap of GAD67-GFP axons and varicosities on the soma and proximal dendrites of NF-M-positive neurons in layer IV (data not shown). Our results showed that the number of perisomatic GFP boutons near an NF-M-positive cell was significantly reduced in sensory-deprived brains (via whisker-trimmed rows A-E; $22 \pm 4 \% ; n=5$ mice). Similarly to the results with GFP-positive boutons, PV-positive boutons were also significantly decreased in whisker-trimmed animals (whisker-trimmed rows A-E; $28 \pm 3 \% ; n=5$ mice).

Both PV (see above, Differential expression of PV in layer IV GAD67-GFP interneurons in sensory-deprived and -spared cortices) and GAD67 expression are thought to be bidirectionally modulated by sensory experience (Welker et al., 1989); we therefore used polyclonal rabbit anti-GAD65/67 as an alternative method to examine changes in synaptic inhibition. In this experiment, average grayscale fluorescent intensity of GAD65/67-IR near a spiny neuron was measured instead of the number of individ- 
ual inhibitory synaptic boutons. GAD65/ 67-IR was found in cell bodies of GABAreleasing interneurons and synaptic terminals of GABA-releasing interneurons. In neocortex, abundant GAD65/67-positive GABAergic terminals were also found in perisomatic site of pyramidal neurons and spiny neurons (Fukuda et al., 1998; Ekstrand et al., 2001). Because of the close localization of these inhibitory synapses in the cell body and the basket formation of the perisomatic inhibitory synapses, the cell body of these glutamatergic cells appears to be positive for GAD65/67 (Fig. 4, compare A1, A2). In this study, the majority of these cells were presumed spiny neurons [i.e., these cells were GFP negative (Fig. 4, compare A1, A2)]; the remaining cells were GAD67GFP interneurons [i.e., GFP positive (Fig. 4, compare A3, A4 and A5, A6)] and a negligible proportion of GFP-negative interneurons (data not shown). Inhibitory synapses of the GAD67-GFP neurons were also abundant at the perisomatic sites on GAD65/67-positive neurons (Fig. 4, compare $A 1, A 2$, the cell marked by an asterisk). Measurements of GAD65/67-IR in randomly sampled GFP-negative and presumed spiny cells showed a $50 \pm 3 \%$ decrease in the expression of GAD65/67 in spiny cells (Fig. 4 B2) $(p<0.0001 ; n=30$ cells in deprived and spared sites, respectively; $n=25$ cells in control brain) of a deprived area. Indeed, the reduction of GAD-IR is greater than the reduction of PV- or GFP-positive boutons. We next examined whether GAD expression and GFP-IR were different between spared and deprived barrels. Measurements of GAD-IR were performed in GFP-positive neurons. Our results showed a significant reduction $(15 \pm 2 \%)$ in the GAD expression of the GFP-positive interneurons (Fig. $4 D 1)$ ( $n=30$ cells in deprived and spared regions, respectively; $n=25$ cells in control brain; $p<0.01$ vs control and spared, respectively). Interestingly, the GFP-IR intensities were similar in different barrels (Fig. 4D1). In fact, scatter plot analysis showed no correlation between the GFP-IR and the GAD-IR (Fig. 4D2). In cells expressing very low levels of GADIR, the GFP expression was very robust (Fig. 4D2, gray arrow and circle). These results suggest that the reduction in the number of GFP-positive boutons is not attributable to downregulation of GFP expression in the GAD67-GFP cells per se.
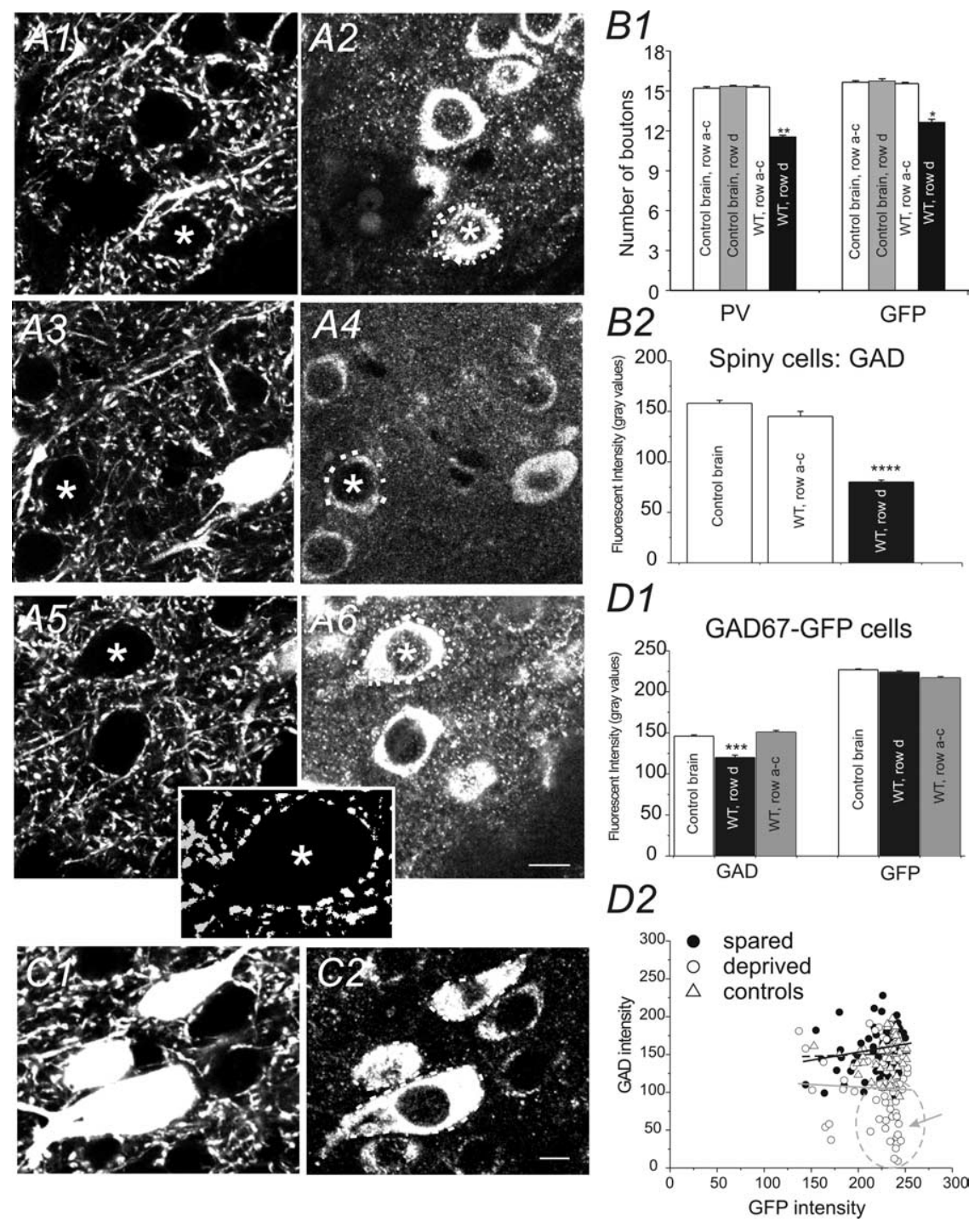

Figure 4. Effects of row-D WT on perisomatic inhibitory boutons and GAD expression in barrel cortex layer IV. Photomicrographs of GFP $(\boldsymbol{A 1}, \boldsymbol{A 3}, \boldsymbol{A 5})$ and GAD65/67-IR $(\boldsymbol{A 2}, \boldsymbol{A 4}, \boldsymbol{A 6})$ in layer IV barrel cortex. $\boldsymbol{A 1}, \boldsymbol{A 2}, \mathrm{A}$ section from a control untreated mouse. A3, A4, Micrographs of the deprived row (D) from WT-treated mouse. A5, A6, Micrographs from the spared row of the same WT-treated mouse. Scale bars, $10 \mu \mathrm{m}$. Dotted white lines in $\mathbf{A 2}, \mathbf{A 4}$, and $\boldsymbol{A} \mathbf{6}$ demarcate GFP-negative areas (cell bodies of presumed spiny neurons, marked by asterisks) innervated by GFP-positive boutons in $\boldsymbol{A 1}, \boldsymbol{A 2}$, and $\boldsymbol{A} \mathbf{3}$, respectively. $\boldsymbol{A} \mathbf{5}$, Inset, Digitally enhanced micrograph of the perisomatic GFP puncta marked by an asterisk in $\boldsymbol{A 5}$. The automeasure counting of the number of the GFP-positive presynaptic varicosities was derived from these digitally enhanced boutons (see Materials and Methods). B1, Number of PV-positive and GFP-positive perisomatic varicosities near a presumed spiny neuron in barrels of tangential slices from control (white and gray bars) and whisker-trimmed (row-D trimmed) mice (black bars). ${ }^{* *} p<0.01 ;{ }^{*} p<0.05 ; n=$ 5 brains for controls and WT-treated mice, respectively. B2, Fluorescent intensities for GAD65/67-IR (measured by mean gray scales for red pixels) in presumed spiny neurons demarked by the GFP-positive presynaptic varicosities $(\boldsymbol{A 2}, \boldsymbol{A 4}, \boldsymbol{A 6})$ in TC slices from control mice (white bar), deprived region (row D; black bar), and spared region (rows A-C; white bar) of WT-treated mice, respectively. ${ }^{* * *} p<0.0001$ versus control and spared; no statistical significance between spared and controls, $n=5$ brains for controls and WT-treated mice, respectively. C, Photomicrographs of GFP (C1) and GAD65/67-IR (C2) in layer IV barrel cortex of a naive untreated GAD67-GFP mouse. Dotted lines (white) in C2 demarcate the perikaryon of the GFP-positive neurons. D1, Bar graph shows changes in expression of GAD65/67-IR and GFP in the GFP cells located in barrels of control, deprived, and spared cortices. ${ }^{* * *} p<0.001$. D2, Scatter plot shows the relationship between expression of GFP and GAD65/67-IR in barrels of control mice (open triangles) and WT-treated mice [spared (filled circles) and deprived (open circles) sites, respectively]. Note that many of the cells expressing lower levels of GAD65/67-IR showed higher gray values (marked by a gray circle and arrow). Solid gray line, Linear fitting for the scatter plot of deprived barrels; solid black line, linear fitting for the scatter plot of spared barrels; dotted black line, linear fitting for the scatter plot of controls. Error bars represent SEM.
Sensory deprivation induced small but significant changes in the properties of miniature IPSCs in spiny neurons

Patch-clamp recordings were made from spiny neurons located in the barrel cortex (layer IV) of GAD67-GFP mice (e.g., Fig. 5A).
Spiny neurons were defined based on (1) their identification as GFP negative (Fig. 5B) and (2) their characteristic firing pattern (Fig. 5C). For the recording of IPSCs, cesium-based patch pipette solution was used. In this case, immediately after membrane rup- 

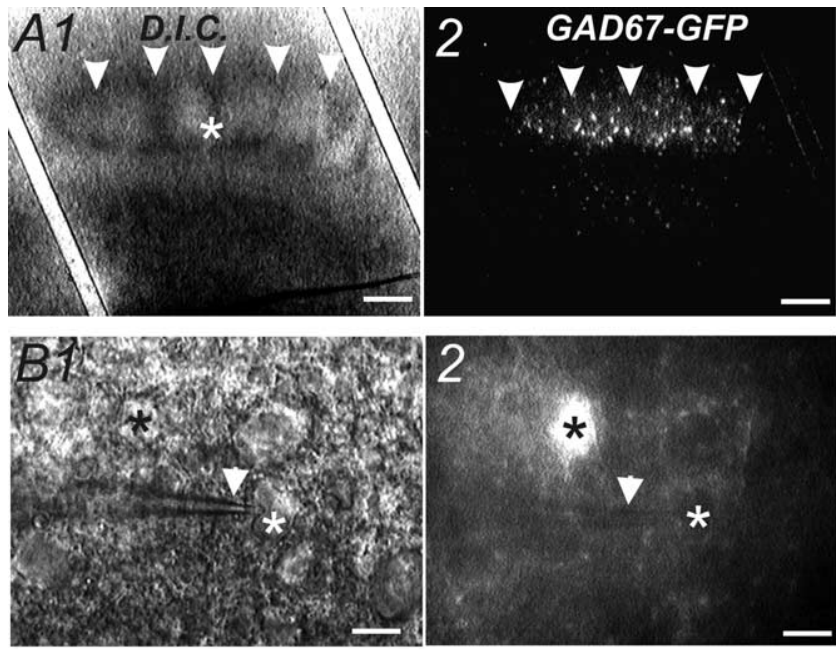

C1

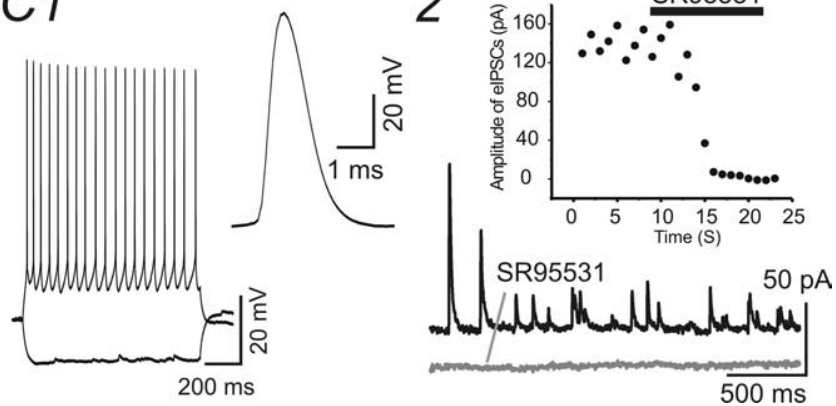

Figure 5. Patch-clamp recording of GABAergic inhibitory synaptic currents from spiny neurons. A1, Photomicrograph of a TC slice viewed via bright-field microscopy. A1, A2, Arrowheads, Barrel septum. A2, Photomicrograph of the same TC slice viewed via epifluorescent microscopy. White asterisk indicates the site at which whole-cell recording was made. Scale bars, $150 \mu \mathrm{m}$. Note the high density of GFP-positive cells in layer IV barrel field. B1, A highermagnification photomicrograph of the TC slice from A1 viewed via DIC microscopy. B1, B2, White asterisks, Patch-clamp recording was made from a spiny neuron, which was the same cell shown in $\mathbf{B} 2$ and is negative for GFP; black asterisks, a GFP-positive cell; white arrowheads, patch-clamp pipette. Scale bars, $10 \mu \mathrm{m}$. C1, Left, Action potentials and membrane hyperpolarization were elicited from the cell from $\boldsymbol{B} \mathbf{1}$ by hyperpolarizing and depolarizing current of $\pm 100 \mathrm{pA}$. Right, A single action potential of the same cell. $\mathbf{2}$, Outward evoked and spontaneous IPSCS (top trace) were blocked by SR95531 (10 $\mu$ m; bottom trace).

turing, current-clamp recording was performed to identify the firing pattern (data not shown). After the pipette solution had completely diffused into the cell, voltage-clamp recordings were performed. Cells were recorded with a holding potential of $0 \mathrm{mV}$ to minimize the EPSC currents (Fig. 5C). The GABAergic nature of the outward IPSCs was verified via local perfusion of $\mathrm{GABA}_{\mathrm{A}}$ receptor antagonist SR95531 (Fig. 5C). We first recorded miniature IPSCs in spiny neurons located in spared barrels (rows A-C) and in deprived barrels (row D). The properties of the mIPSCs had small but significant differences. These differences were as follows: (1) the mean amplitudes of mIPSCs in deprived barrels were significantly smaller (Fig. 6, Table 1); (2) the half-width and

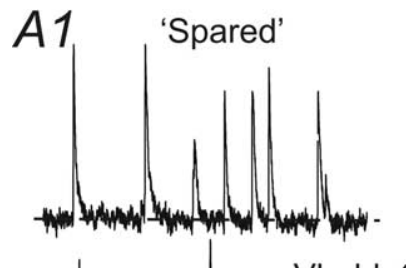

B1 'Deprived'
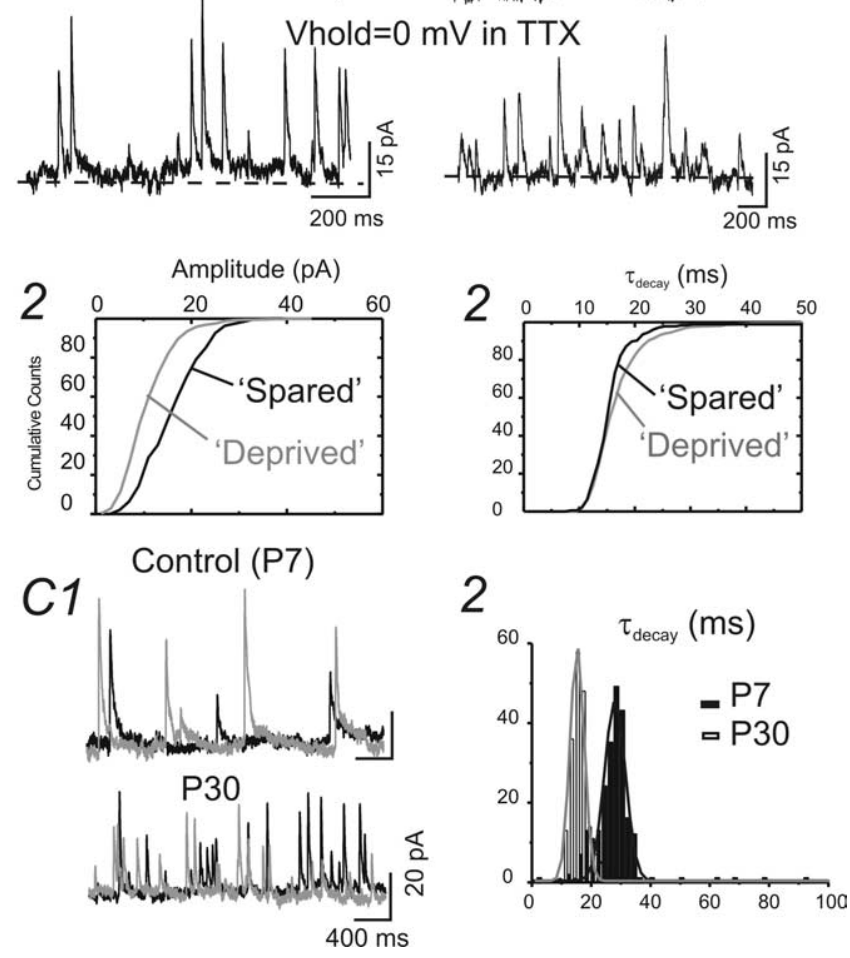

Figure 6. Properties of mIPSCs recorded in spiny neurons in control (P7 and P30) and WTtreated brain slices. $\boldsymbol{A} \mathbf{1}, \boldsymbol{B} \mathbf{1}, \mathrm{mIPSC}$ recorded in a spiny neuron located in spared regions $(\boldsymbol{A} \mathbf{1})$ and in deprived region $(B 1)$ in barrel cortex layer IV. $V_{\text {hold }}=0 \mathrm{mV}$. Dashed line, level of holding current. $\boldsymbol{A 2}, \mathbf{B 2}$, Cumulative distribution of amplitudes (A2) and time constants of decay $\left(\tau_{\text {decay }} ;\right.$ $B 2$ ) for mIPSCs of $\boldsymbol{A} 1$ and $B 1$. C1, $\mathrm{mIPSC}$ recorded in a spiny neuron located in barrel cortex layer IV of a control P7 (top traces) mouse and a P30 (bottom traces) mouse. C2, Histogram of the decay time constant $(\tau)$ for the mIPSC in C1. Note that the decay $\tau$ is shorter in mIPSCs recorded in the P30 mouse. Black and gray traces were obtained from sequential recordings. Solid lines, The distribution of the $\tau$ was fitted with multipeak Gaussian distribution (see Materials and Methods). The gray line was fitted for data obtained from P30. The black line was fitted for data obtained from P7.

decay time of the mIPSCs were larger in deprived barrels (Fig. 6, Table 1); and (3) the frequency of mIPSCs were much smaller than spared regions (Fig. 6, Table 1). In contrast, properties of mIPSCs in spared regions were similar to those of naive untreated controls (Table 1). These results suggest that sensory inputs either increase or maintain the amplitude of mIPSC during development. To discriminate between these two possibilities, we examined mIPSCs in spiny neurons of 7-d-old mice. Our results showed that many of the properties of mIPSCs in deprived neurons [such as slowing of half-width, increase in $\tau_{\text {decay }}$, increase in

Table 1. Comparison of properties of mIPSCs from spiny neurons in spared and deprived barrels of treated mice and controls (P30 and P7)

\begin{tabular}{|c|c|c|c|c|c|c|c|}
\hline Location & $\begin{array}{l}\text { Amplitude } \\
\text { (pA) }\end{array}$ & $\begin{array}{l}\text { Half-width } \\
\text { (ms) }\end{array}$ & $\tau_{\text {decay }}(\mathrm{ms})$ & CV & $\begin{array}{l}\text { Instant } \\
\text { frequency }\end{array}$ & $R_{\text {in }}(\mathrm{M} \Omega)$ & $n$ \\
\hline Spared & $17 \pm 0.2$ & $35 \pm 0.5$ & $16 \pm 1.0$ & $0.4 \pm 0.1$ & $15 \pm 5$ & $245 \pm 31$ & 22 \\
\hline Deprived & $11 \pm 0.2^{*}$ & $38 \pm 0.6^{* *}$ & $17 \pm 0.2^{* *}$ & $0.5 \pm 0.1^{* *}$ & $6 \pm 0.6^{*}$ & $217 \pm 37^{*}$ & 20 \\
\hline Controls (P30) & $16 \pm 0.3$ & $36 \pm 1$ & $16 \pm 1.0$ & $0.4 \pm 0.1$ & $14 \pm 2$ & $252 \pm 27$ & 35 \\
\hline Controls (P7) & $24 \pm 5^{* *}$ & $43 \pm 1.9^{* *}$ & $30 \pm 3^{*}$ & $0.5 \pm 0.1^{* *}$ & $3 \pm 1.4^{*}$ & $221 \pm 41^{* *}$ & 15 \\
\hline
\end{tabular}

$C \mathrm{~V}$, Coefficient of variation for mIPSC amplitude; $R_{\mathrm{in}}$ input resistance. ${ }^{*} p<0.01$ and ${ }^{* *} p<0.05$, deprived versus spared and P7 versus $\mathrm{P} 30$ controls. 

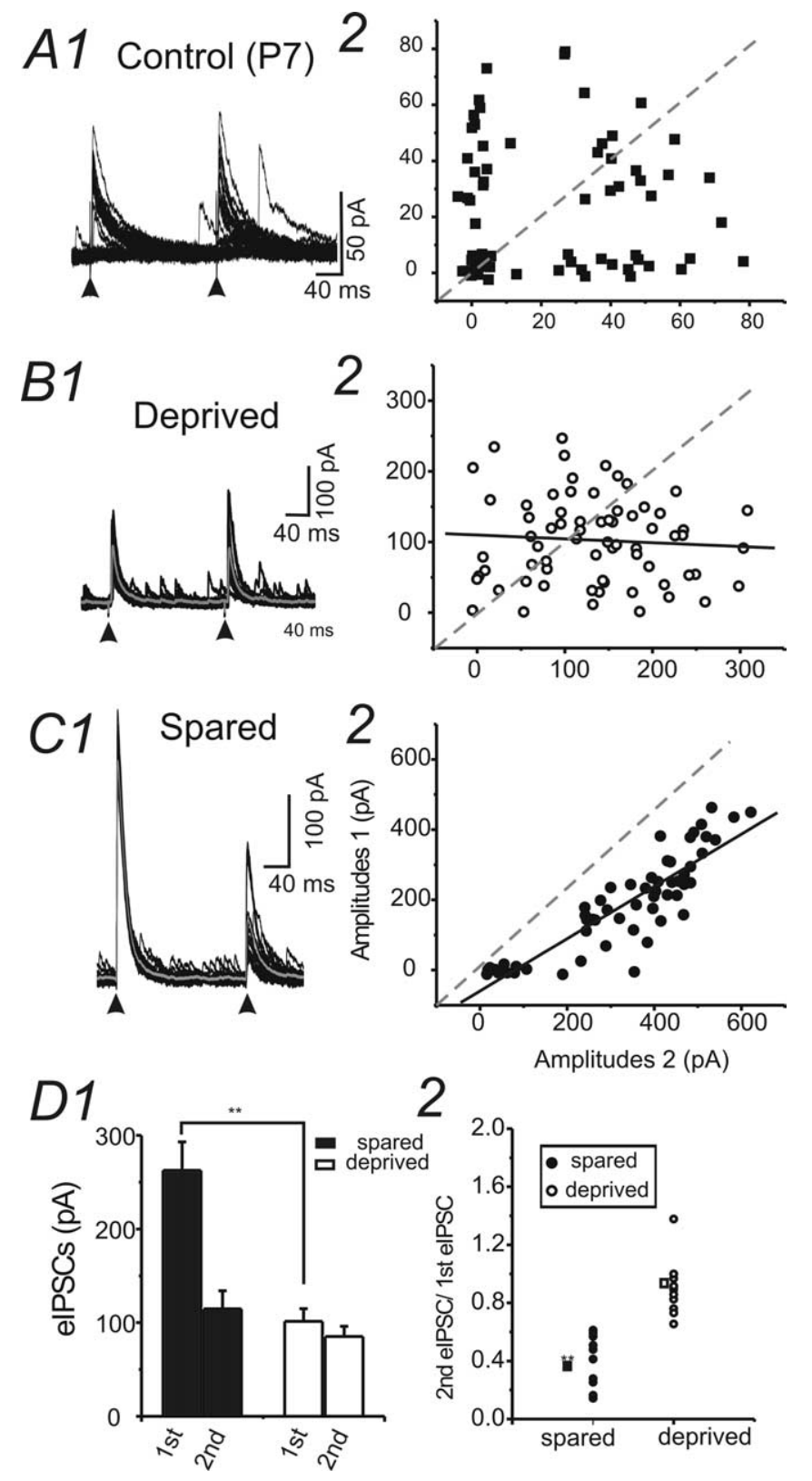

Figure 7. Properties of elPSCs recorded in spiny neurons in control (P7 and P30) and WTtreated brain slices. $\boldsymbol{A 1}$, Example of elPSCs evoked by extracellular stimuli at an interval of 200 $\mathrm{ms}$ in a cell in barrel cortex layer IV of a P7 mouse. $V_{\text {hold }}=0 \mathrm{mV}$. $\mathbf{A 2}$, Amplitudes of elPSC1 were plotted against the amplitudes of eIPSC 2 in the same cell. Dashed lines, Level at which amplitudes of elPSC1 equal amplitudes of elPSC2.B1, C1, Examples of elPSCs evoked by extracellular stimuli at an interval of $200 \mathrm{~ms}$ in cells located in spared regions (C1) and in deprived region (B1) in barrel cortex layer IV. $V_{\text {hold }}=0 \mathrm{mV}$. Thicker gray traces, Averaged trace for recordings. Arrowheads, paired pulses. B2, C2, Amplitudes of elPSC1 were plotted against the amplitudes of elPSC 2 in the same cell. Solid black line, Linear fitting for the scatter plot. Dashed line, Level at which amplitudes of elPSC1 equal amplitudes of eIPSC2. Note that in the cell from C1, amplitudes of elPSC2 were always smaller than the amplitudes of elPSC1; therefore, the data points were all located below the dashed line. However, in the cell from $\boldsymbol{B} \mathbf{1}$, a similar pattern of distribution did not exist. D1, The mean amplitudes of elPSCs evoked by the extracellular stimuli in spared and deprived barrels. Error bars represent SEM. ${ }^{* *} p<0.01 ; n=10$ for each group. D2, The paired-pulse ratio of elPSCs in cells located in spared (filled circles) and deprived (open circles) barrels. ${ }^{* *} p<0.01 ; n=10$ for each group.

coefficient of variation (CV), and reduction in frequency] were similar to those of mIPSCs of P7 mice (Fig. 6C, Table 1). However, the amplitude of mIPSCs in young mice (P7) was significantly larger than that recorded in P30 mice and than that for deprived cortex. These results suggest that the role of activity during postnatal development is not simply to maintain or increase the quantal distribution of IPSCs.

\section{Sensory deprivation induced robust presynaptic and postsynaptic changes in evoked intracortical inhibitory synaptic transmission}

Intracortical inhibitory synaptic potentials were evoked via extracellular tungsten bipolar stimulating electrodes placed $\sim 100 \mu \mathrm{m}$ from the recording electrodes. A near threshold (minimal) stimulus protocol was used to measure small intracortical inhibitory responses (see Materials and Methods) (cf. Xiang et al., 1998). In naive untreated brain, the evoked IPSCs showed typical robust paired-pulse depression (cf. Sun et al., 2006). We found that the properties of eIPSCs were different in deprived and spared barrels (Fig. 7). The most notable difference was that the amplitudes of eIPSCs ( $V_{\text {hold }}=0 \mathrm{mV}$ ) were much smaller in the deprived barrels (Fig. 7, compare B1, C1; D1). The second noticeable difference was that there was a switch in the paired-pulse ratio from a strong paired-pulse depression in spared cortices to a weak paired-pulse depression or paired-pulse facilitation in the deprived cortices (Fig. 7, compare $C, B$ and $C, D 2$ ). These results suggest that the synaptic properties of intracortical inhibitory transmission are differentially regulated by postnatal sensory experiences. Lack of sensory activities alters both the presynaptic strength and shortterm plasticity of intracortical inhibitory synapses. We also compared the results with eIPSCs recorded in young mice (P7) (Fig. $7 A$ ). Our results showed that the eIPSCs recorded at P7 shared many similarities with eIPSCs recorded in adult deprived cortex: much smaller amplitudes ( $41 \pm 4 \mathrm{pA} ; n=10$ cells), larger CVs $(0.76 \pm 0.1)$, and lack of paired-pulse depression (Fig. 7, compare $A, B)$ (paired-pulse ratio, $1.0 \pm 0.2$ ). In addition to these changes related to presynaptic properties, we also found changes in the $\tau_{\text {decay }}$, which showed a significant increase $(21 \pm 2$ vs $16 \pm 1 \mathrm{~ms}$; $n=12$ cells in deprived and $n=15$ cells in spared; $p<0.01$ ) compared with that recorded in spared sites.

We next applied the stimulus with graded intensity to elicit IPSCs with varied amplitudes. We then plotted the amplitude distribution histogram of the evoked events. The distribution histogram was fitted by multipeak waveform with Gaussian distribution (see Materials and Methods). Typical evoked events show two to three evoked peaks in Gaussian fitted curves. This approach was used previously to estimate upregulation of inhibitory "quanta size" in epileptic regions (Nusser et al., 1998). We used a different approach, i.e., the intensity of stimulation was increased at small steps, which may have recruited more presynaptic fibers. Using this approach, we found that the $\Delta$ value between these peaks (i.e., estimated quantal value) were similar in value to the amplitudes and conductance of unitary IPSCs onto spiny cells provided by basket cells but not dendritic targeting cells (cf. Xiang et al., 2002; Sun et al., 2006). Indeed, these $\Delta$ values were also similar to the amplitudes of eIPSCs evoked by minimal stimulus (Fig. 8A2, B2). These data are consistent with the idea that the evoked inhibitory responses were primarily unitary IPSCs formed at perisomatic sites. We found that there was a significant $(p<0.001)$ and robust (more than onefold) reduction in the value of fitted multiple peaks (i.e., amplitudes of unitary IPSCs) in deprived neurons (Fig. 8C). These results suggest that postnatal sensory activities in vivo are necessary for the transformation of functional inhibitory transmission from an immature to a mature phenotype. 

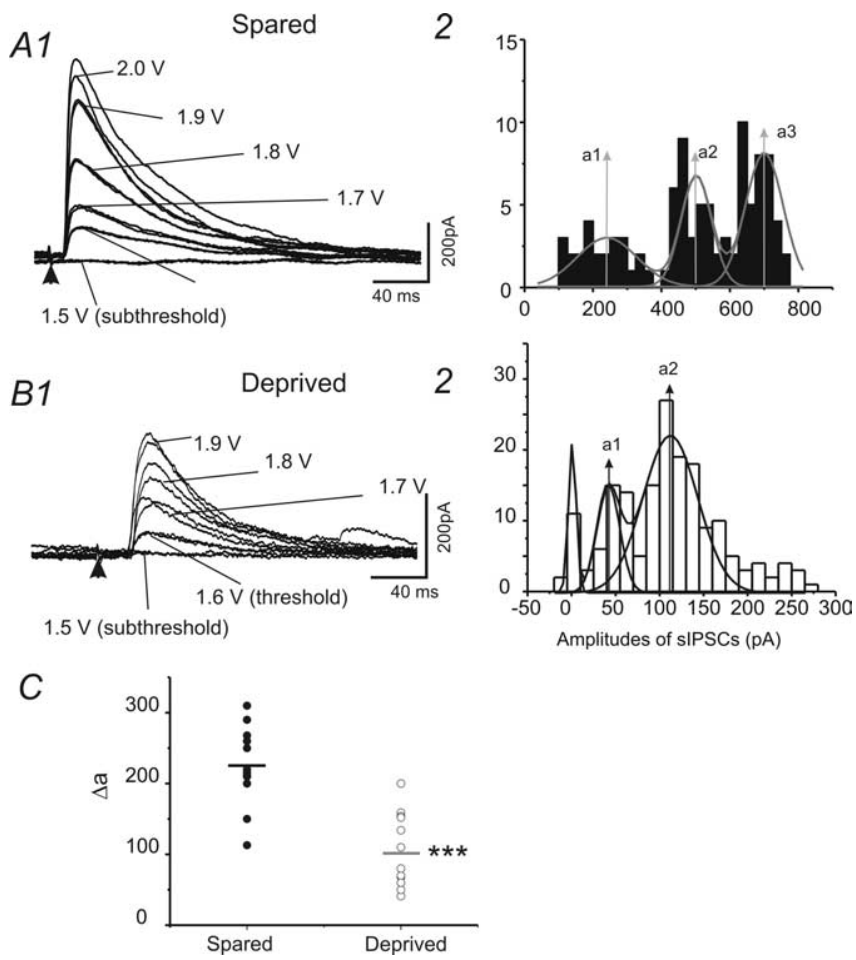

Figure 8. Properties of elPSCs recorded in spiny neurons in control and WT-treated brain slices. $\boldsymbol{A 1}, \boldsymbol{B} 1$, Examples of elPSCs evoked by extracellular stimuli with graded intensity (from subthreshold to suprathreshold) in cells located in spared regions ( $\boldsymbol{A} \boldsymbol{1})$ and in deprived region (B1) in barrel cortex layer IV. $V_{\text {hold }}=0 \mathrm{mV} . \mathbf{A 2}, \mathbf{B 2}$, Histograms of amplitudes of elPSCs in recordings of $\boldsymbol{A} \mathbf{1}$ and $\boldsymbol{B}$, respectively. The distribution of the amplitudes was fitted with multipeak Gaussian distribution. a1-a3, Values of the centers of the peaks (see Materials and Methods). C, Scatter graph showing the value of mean $\Delta$ a (mean value of $\Delta$ as in a single recording) in spared (filled circles) and deprived (open circles) cells. ${ }^{* * *} p<0.001$ ( $n=12$ for spared and deprived, respectively).

\section{Discussion \\ Maturation of inhibitory networks and its dependence on sensory experiences}

Changes in the number of parvalbumin-positive interneurons parallel visual critical period onset (Gao et al., 2000), suggesting an experience-dependent regulation of specific GABAergic circuitry. However, direct experimental evidence linking specific structural and functional changes of the GABAergic inhibitory networks with previous sensory experiences in vivo is largely lacking. In an early study, Chattopadhyaya et al. (2004) showed that intraocular TTX injections induced a reduction in the density of perisomatic synapses formed by parvalbumin-expressing cells and that this sensitivity was restricted to a critical time window. These in vivo data are consistent with results of this study in the somatosensory cortex. In the barrel cortex, paramount evidence is available linking changes in the properties of excitatory synapses and receptive field properties with previous sensory experiences (Shepherd and Svoboda, 2005; Shoykhet et al., 2005). However, quantitative analysis of properties of inhibitory networks influenced by sensory experiences is lacking.

Our results showed that specific structural and anatomical changes (i.e., the number of perisomatic inhibitory synapses) occurred in specific types (i.e., PV positive) of interneurons and that these changes were associated with a lack of sensory experience during the second and the third postnatal week. Because both PV (demonstrated by this study) and GAD67 (Welker et al., 1989) interneurons are bidirectionally modulated by sensory ex- periences in the barrel cortex, there is a possibility that the percentage reduction in perisomatic boutons, as measured by GFP or PV immunoreactivity, in the deprived barrels is incorrectly estimated. However, when we measured the GFP expression in single cells, we did not find significant changes in the intensity of GFP expression. Indeed, when we carefully examined the GFP+ cells, in which GAD-IR showed marked reduction (Fig. 4D2), the GFP intensity was not downregulated. A reasonable explanation for this result is that during the initiation of GFP expression, the GAD promoter plays an important role. However, once the process begins, GFP expression is no longer regulated by the promoter. In addition, GFP was very stable in vivo. Thus, GFP fluorescence, which might be a sum of current and previous gene expression events, may not accurately reflect transcription activation of an endogenous target gene (cf. Yamaguchi et al., 2000; Yu et al., 2003).

We also found that the reduction of presynaptic perisomatic inhibitory boutons was found to exist concomitantly with functionally abnormal inhibitory synaptic transmission in spiny neurons. In the barrel cortex, sensory deprivation reduces the release probability of GABAergic synapses and the amplitude of mIPSCs. The reduction in the number of perisomatic inhibitory synaptic boutons is consistent with results reported in the visual cortex in vitro and in vivo (Morales et al., 2002; Chattopadhyaya et al., 2004). For the evoked IPSCs, the eIPSCs recorded in P7 share many similarities with eIPSCs recorded in adult deprived cortex: smaller amplitudes, larger CVs, and a lack of paired-pulse depression (Fig. 7, compare $A, B$ ). These results suggest that the postnatal sensory activities in vivo are necessary for the transformation of functional inhibitory transmission from an immature to a mature phenotype. However, the story of mIPSCs is far more complex. First of all, many properties of IPSCs in deprived neurons, such as the slowing of half-width, increase in $\tau_{\text {decay }}$, increase in $\mathrm{CV}$, and reduction in frequency are similar to those of IPSCs in P7 mice (Fig. 6C, Table 1). However, the amplitude of mIPSCs in young mice (P7) is significantly larger than that recorded in P30 mice and deprived cortex (Table 1). Similar results in the developmental regulation of amplitudes and properties of mIPSCs and sIPSCs have been reported in the developing visual cortex (Bosman et al., 2005). Thus, it seems that the role of activity during postnatal development is not relegated to simply maintaining or increasing the quantal distribution of IPSCs. Postsynaptic changes such as $\mathrm{GABA}_{\mathrm{A}}$ receptor composition, number of release sites per fiber, and the cellular location of the synapses (i.e., dendrites vs cell body) are all likely to be altered.

Several previous studies documented the effects of sensory deprivation on the GABA system in the barrel cortex. In one such study, WT starting from postnatal day 1 reduced the GABAergic cell count by $>50 \%$ in layer IV (Micheva and Beaulieu, 1995). It is not clear whether this reduction was caused by reduced GABA immunoreactivity in intact interneurons or an overall reduction of GABAergic interneurons. Taking advantage of the intrinsic expression of GFP in the majority of GABAergic cells ( 97\%) (cf. Tamamaki et al., 2003), our results showed that whereas the total number of GAD67 cells (i.e., total number of GABAergic cells) remained unchanged, changes in the expression of PV from basket cells appeared to be the major effect of sensory deprivation. In another study, although there were no statistically significant changes in the quantitative distribution of the overall GABAergic synaptic population, there is a specific loss of as many as twothirds of the GABA contacts targeting dendritic spines (Micheva and Beaulieu, 1995). Compared with this study, we found that WT beginning at the second postnatal week similarly downregu- 
lated the GABAergic perisomatic boutons. We have not studied specifically whether dendritic inhibitory synapses were affected. However, our electrophysiological results showed a reduction in the amplitude of evoked intracortical inhibitory synaptic potentials, which are primarily generated by perisomatic synapses (Morales et al., 2002; Sun et al., 2006).

\section{Network and developmental consequences of altered intracortical inhibitory synaptic transmission}

Activity-dependent maturation of visual cortex and its critical periods is triggered by the functional maturation of local inhibitory connections and driven by a specific, late-developing subset of interneurons. Therefore, changes in global-level intracortical inhibition are likely to delay or accelerate the formation of critical periods. For example, mice lacking synaptic GAD65 do not exhibit ocular dominance plasticity unless an appropriate level of GABAergic transmission is restored by direct infusion of benzodiazepines into the brain (Fagiolini and Hensch, 2000). A potential weakness of this study is the use of GAD67 knock-in mice, whose construction reduces endogenous GABA levels (Tamamaki et al., 2003). To address this issue, additional experiments were performed in wild-type GFP-negative mice. Indeed, we found that the same WT paradigm induced higher percentage reduction in the level of PV in deprived barrels [38\% in wild-type mice vs $20-29 \%$ in two different WT models in the GAD67-GFP mice (Fig. 1C)]. Thus, experience-dependent plasticity of inhibitory networks still exists, although it appears to be less robust, in the GAD67 mice. A possible explanation is that although the endogenous level of GAD is lower in GAD67-GFP mice than normal wild-type mice, active whisking after postnatal periods can significantly upregulate the emergence of mature inhibition in the barrel cortex (Knott et al., 2002). The second possibility is that an effect of reducing the endogenous level of GAD67 is to delay or prolong the critical periods for whisker-induced cortical plasticity. Such possibilities may be further examined in developmental studies to compare the critical periods between wild-type and GAD67-GFP mice. In the visual cortex, enhancing or reducing tonic levels of GABA by diazepam (selective GABA agonist) infusion prematurely closes critical periods for monocular deprivation (Iwai et al., 2003).

What are the network and functional consequences of a downregulation of intracortical perisomatic inhibitory transmission in the barrel cortex? In the behaving animal, each barrel uses multiwhisker thalamic inputs and local inhibitory circuitry to sharpen the receptive field properties of its constituent neurons (for review, see Alonso and Swadlow, 2005). Cortical disinhibition, as a consequence of selective whisker removal, is likely to be an important factor underlying altered receptive field properties in sensory-deprived animals (Kelly et al., 1999). In a recent study, Shoykhet et al. (2005) reported that WT, both from P0 and P12, led to enlarged excitatory and weakened inhibitory receptive fields in layer IV neurons. Currently, cellular mechanisms underlying experience-dependent plasticity of inhibitory receptive fields remain unclear. However, two main processes are likely to contribute to an altered receptive field: (1) recruitment of inhibitory interneurons by thalamocortical and intracortical excitatory synaptic transmission and (2) the output of local inhibitory interneurons. Our results clearly demonstrate a deficit in perisomatic inhibitory synaptic transmission and synaptic terminals. We used these two protocols (D-row whisker trimmed vs all-row trimmed) to delineate whether intracortical activities from spared barrels are necessary for the downregulation of PV expression and GABAergic synapses (cf. Kelly et al., 1999). We have not found any significant differences in the percentage of reduction in PV or number of GABAergic synapses in sensory-deprived cortices in the two different models. This suggests that whiskerspecific thalamocortical activities and downstream local cortical activities, and not activities provided by surrounding whiskers, are important for the postnatal maturation of inhibitory networks. In the all-row-trimmed group, there is a small but significant increase in the number of GFP-positive neurons (Fig. 3C1). These additional neurons are likely to be nonbasket and dendritic targeting cells, whose increase may be a result of increased intracortical activities in this model (cf. Kelly et al., 1999; Shepherd and Svoboda, 2005).

\section{References}

Agmon A, Connors BW (1991) Thalamocortical responses of mouse somatosensory (barrel) cortex in vitro. Neuroscience 41:365-379.

Agmon A, Hollrigel G, O’Dowd DK (1996) Functional GABAergic synaptic connection in neonatal mouse barrel cortex. J Neurosci 16:4684-4695.

Alonso JM, Swadlow HA (2005) Thalamocortical specificity and the synthesis of sensory cortical receptive fields. J Neurophysiol 94:26-32.

Bosman LW, Heinen K, Spijker S, Brussaard AB (2005) Mice lacking the major adult GABAA receptor subtype have normal number of synapses, but retain juvenile IPSC kinetics until adulthood. J Neurophysiol 94:338-346.

Chattopadhyaya B, Di Cristo G, Higashiyama H, Knott GW, Kuhlman SJ, Welker E, Huang ZJ (2004) Experience and activity-dependent maturation of perisomatic GABAergic innervation in primary visual cortex during a postnatal critical period. J Neurosci 24:9598-9611.

Ekstrand JJ, Domroese ME, Feig SL, Illig KR, Haberly LB (2001) Immunocytochemical analysis of basket cells in rat piriform cortex. J Comp Neurol 434:308-328.

Fagiolini M, Hensch TK (2000) Inhibitory threshold for critical-period activation in primary visual cortex. Nature 404:183-186.

Fagiolini M, Fritschy JM, Low K, Mohler H, Rudolph U, Hensch TK (2004) Specific GABAA circuits for visual cortical plasticity. Science 303: $1681-1683$.

Feldman DE, Brecht M (2005) Map plasticity in somatosensory cortex. Science 310:810-815.

Fukuda T, Aika Y, Heizmann CW, Kosaka T (1998) GABAergic axon terminals at perisomatic and dendritic inhibitory sites show different immunoreactivities against two GAD isoforms, GAD67 and GAD65, in the mouse hippocampus: a digitized quantitative analysis. J Comp Neurol 395:177-194.

Gao WJ, Wormington AB, Newman DE, Pallas SL (2000) Development of inhibitory circuitry in visual and auditory cortex of postnatal ferrets: immunocytochemical localization of calbindin- and parvalbumincontaining neurons. J Comp Neurol 422:140-157.

Hayes TL, Lewis DA (1992) Nonphosphorylated neurofilament protein and calbindin immunoreactivity in layer III pyramidal neurons of human neocortex. Cereb Cortex 2:56-67.

Heinen K, Bosman LW, Spijker S, van Pelt J, Smit AB, Voorn P, Baker RE, Brussaard $\mathrm{AB}$ (2004) GABAA receptor maturation in relation to eye opening in the rat visual cortex. Neuroscience 124:161-171.

Hensch TK, Stryker MP (2004) Columnar architecture sculpted by GABA circuits in developing cat visual cortex. Science 303:1678-1681.

Hensch TK, Fagiolini M, Mataga N, Stryker MP, Baekkeskov S, Kash SF (1998) Local GABA circuit control of experience-dependent plasticity in developing visual cortex. Science 282:1504-1508.

Hornung JP, Riederer BM (1999) Medium-sized neurofilament protein related to maturation of a subset of cortical neurons. J Comp Neurol 414:348-360.

Iwai Y, Fagiolini M, Obata K, Hensch TK (2003) Rapid critical period induction by tonic inhibition in visual cortex. J Neurosci 23:6695-6702.

Kelly MK, Carvell GE, Kodger JM, Simons DJ (1999) Sensory loss by selected whisker removal produces immediate disinhibition in the somatosensory cortex of behaving rats. J Neurosci 19:9117-9125.

Knott GW, Quairiaux C, Genoud C, Welker E (2002) Formation of dendritic spines with GABAergic synapses induced by whisker stimulation in adult mice. Neuron 34:265-273.

McMullen NT, Smelser CB, Rice FL (1994) Parvalbumin expression reveals a vibrissa-related pattern in rabbit SI cortex. Brain Res 660:225-231. 
Micheva KD, Beaulieu C (1995) An anatomical substrate for experiencedependent plasticity of the rat barrel field cortex. Proc Natl Acad Sci USA 92:11834-11838.

Morales B, Choi SY, Kirkwood A (2002) Dark rearing alters the development of GABAergic transmission in visual cortex. J Neurosci 22: $8084-8090$.

Nelson SB (1991) Temporal interactions in the cat visual system. I. Orientation-selective suppression in the visual cortex. J Neurosci 11:344-356.

Nusser Z, Hajos N, Somogyi P, Mody I (1998) Increased number of synaptic GABA(A) receptors underlies potentiation at hippocampal inhibitory synapses. Nature 395:172-177.

Shepherd GM, Svoboda K (2005) Laminar and columnar organization of ascending excitatory projections to layer $2 / 3$ pyramidal neurons in rat barrel cortex. J Neurosci 25:5670-5679.

Shoykhet M, Land PW, Simons DJ (2005) Whisker trimming begun at birth or on postnatal day 12 affects excitatory and inhibitory receptive fields of layer IV barrel neurons. J Neurophysiol 94:3987-3995.

Sun QQ, Huguenard JR, Prince DA (2006) Barrel cortex microcircuits: thalamocortical feedforward inhibition in spiny stellate cells is mediated by a small number of fast-spiking interneurons. J Neurosci 26:1219-1230.

Tamamaki N, Yanagawa Y, Tomioka R, Miyazaki J, Obata K, Kaneko T (2003) Green fluorescent protein expression and colocalization with calretinin, parvalbumin, and somatostatin in the GAD67-GFP knock-in mouse. J Comp Neurol 467:60-79.
Vidyasagar TR, Pei X, Volgushev M (1996) Multiple mechanisms underlying the orientation selectivity of visual cortical neurones. Trends Neurosci 19:272-277.

Welker E, Soriano E, Van der Loos H (1989) Plasticity in the barrel cortex of the adult mouse: effects of peripheral deprivation on GADimmunoreactivity. Exp Brain Res 77:666-667.

Wong-Riley M (1979) Changes in the visual system of monocularly sutured or enucleated cats demonstrable with cytochrome oxidase histochemistry. Brain Res 171:11-28.

Woolsey TA, Van der Loos H (1970) The structural organization of layer IV in the somatosensory region (SI) of mouse cerebral cortex. The description of a cortical field composed of discrete cytoarchitectonic units. Brain Res 17:205-242.

Xiang Z, Huguenard JR, Prince DA (1998) GABAA receptor-mediated currents in interneurons and pyramidal cells of rat visual cortex. J Physiol (Lond) 506:715-730.

Xiang Z, Huguenard JR, Prince DA (2002) Synaptic inhibition of pyramidal cells evoked by different interneuronal subtypes in layer $\mathrm{v}$ of rat visual cortex. J Neurophysiol 88:740-750.

Yamaguchi M, Saito H, Suzuki M, Mori K (2000) Visualization of neurogenesis in the central nervous system using nestin promoter-GFP transgenic mice. Neuroreport 11:1991-1996.

Yu YA, Szalay AA, Wang G, Oberg K (2003) Visualization of molecular and cellular events with green fluorescent proteins in developing embryos: a review. Luminescence [Erratum (2003) 18:243] 18:1-18. 